\title{
Usefulness of patency capsule prior to small-bowel capsule endoscopy in clinical practice: Validity of the modified method of patency judgement
}

\section{Takahiro Miyazu}

Hamamatsu University School of Medicine

Satoshi Osawa ( $\sim$ sososawa@hama-med.ac.jp)

Hamamatsu University School of Medicine

\section{Satoshi Tamura}

Hamamatsu University School of Medicine

\section{Shinya Tani}

Hamamatsu University School of Medicine

\section{Natsuki Ishida}

Hamamatsu University School of Medicine

\section{Tomoharu Matsuura}

Hamamatsu University School of Medicine

Mihoko Yamade

Hamamatsu University School of Medicine

Moriya Iwaizumi

Hamamatsu University School of Medicine

Yasushi Hamaya

Hamamatsu University School of Medicine

Takahisa Furuta

Hamamatsu University School of Medicine

Ken Sugimoto

Hamamatsu University School of Medicine

\section{Research Article}

Keywords: patency capsule, small-bowel capsule endoscopy, retention, Crohn's disease

Posted Date: September 30th, 2021

DOI: https://doi.org/10.21203/rs.3.rs-951571/v1 
License: (c) (i) This work is licensed under a Creative Commons Attribution 4.0 International License. Read Full License 


\section{Abstract}

In 2012, Japan approved the use of a tag-less patency capsule (PC), which evaluates gastrointestinal patency before small-bowel capsule endoscopy (SBCE). This study aimed to evaluate the validity of our modification on the passage criteria for this PC in clinical practice. We retrospectively enrolled 326 consecutive patients who underwent PC examination before SBCE. If X-ray could not reveal the PC in the body during the judgement time (30-33 h after ingestion), we defined it as 'estimated patency' and performed SBCE. We employed plain computed tomography (CT) for the second judgement, as needed. The overall patency rate was $95.1 \%$. By X-ray, 41 (12.6\%) patients were judged to have 'estimated patency', and SBCE could be safely performed. Plain CT judgement was necessary in $32.5 \%$. One PC case had a residual coating film associated with stenosis in a patient with Crohn's disease (CD), and one $(0.3 \%)$ SBCE case had capsule retention resulting from false CT judgement. Multivariate analysis revealed that established $C D$ and inpatient were factors related to patency loss. In conclusion, PC is useful for examining gastrointestinal patency, keeping in mind CT misjudgement. If PC was not found in the body via X-ray, performing SBCE as 'estimated patency' seemed appropriate.

\section{Introduction}

Since small-bowel capsule endoscopy (SBCE) was introduced by Iddan et al. in 2000 [1], it has been widely used because of its noninvasiveness and ability to visualise the entire small-bowel mucosa for diagnosing small-bowel pathologies, such as obscure gastrointestinal bleeding (OGIB), small-bowel tumour and inflammation, including Crohn's disease (CD) and NSAID-induced small intestinal injury [26]. However, SBCE occasionally results in capsule retention proximal to stenosis in the gastrointestinal tract $[7,8]$. Capsule retention incidence was reported to be $1.4 \%, 7.4 \%$ and $6.3 \%$ in OGIB, established CD and suspected CD cases, respectively [9]. Balloon-assisted enteroscopy or surgery should be performed to retrieve the capsule $[10,11]$. The Agile ${ }^{T M}$ patency capsule $(P C)$, an ingestible and dissolvable capsule with an external scanner, was developed and used in western countries to assess the functional patency of the small bowel while avoiding capsule retention [12-14].

In Japan, the PillCam ${ }^{T M}$ PC was initially available in 2012 as a tag-less Agile ${ }^{T M}$ PC for safer gastrointestinal evaluation $[3,15,16]$. Passage criteria, which include judging the passage of PillCam ${ }^{\mathrm{TM}}$ PC within 30-33 h after ingestion, are recommended in the enteroscopy practice guidelines [17]. Upon excretion, the medical professional should inspect and palpate the PC to confirm an intact capsule or intact body. If the PC remains in the body but is detected in the large bowel via X-ray, the gastrointestinal tract is considered patent. However, the entry of the PC into the large bowel should be further verified by computed tomography (CT) [18], X-ray tomography [19] or abdominal ultrasonography [20], as necessary. Recently, its safety and usefulness have been reported in larger-scale prospective studies in Japan [21]. However, the methods may need to be modified in daily clinical practice. In fact, some modifications of the passage criteria suitable for daily clinical use were reported to increase the possibility to perform SBCE safely $[22,23]$. 
However, the insights into how to deal with invisible PC excretion via X-ray during the judgement time (30-33 hour after ingestion) and which imaging modality should be used for the second examination after confirming PC location by X-ray remain unknown. In this study, if PC was not detected in the body via X-ray during the judgement time, we considered it as 'estimated patency' before performing SBCE. Plain CT was used as the second imaging tool for judgement. We aimed to evaluate the validity of our modification on the passage criteria suitable for daily clinical practice and evaluated the safety and usefulness of PC in our consecutive cases.

\section{Results}

\section{Patient characteristics}

We enrolled 326 patients, with 198 males and 128 females (Table 1). The mean age was $52.2 \pm 22.2$ years. The most common reason for examination was OGIB $(117,35.9 \%)$, followed by established CD (75, $23.0 \%)$, other inflammatory diseases $(29,8.9 \%)$, abdominal pain $(27,8.3 \%)$, small-bowel tumour (20, $6.1 \%$ ) and suspected CD $(16,4.9 \%)$. History of abdominal surgery, inpatient or outpatient, comorbidities, constipation and use of NSAIDs or LDA are shown in Table 1. 
Table 1

Patients' characteristics

\begin{tabular}{|ll|}
\hline Numbers of patients & 326 \\
\hline Sex, male/female & $198 / 128$ \\
\hline Age, mean \pm SD (range), years & $52.2 \pm 22.2(3-88)$ \\
\hline Inpatient/outpatient & $126 / 200$ \\
\hline History of abdominal surgery, n (\%) & $108(33.1)$ \\
\hline Reason for examination, n (\%) & $117(35.9)$ \\
OGIB & $91(27.9)$ \\
Crohn's disease, overall & $75(23.0)$ \\
Crohn's disease, established & $16(4.9)$ \\
Crohn's disease, suspected & $29(8.9)$ \\
Other inflammatory diseases & $27(8.3)$ \\
Abdominal pain & $20(6.1)$ \\
Small-bowel tumour & $5(1.5)$ \\
Intestinal obstruction & $37(11.3)$ \\
Others & \\
\hline Diabetes mellitus & $51(15.6)$ \\
\hline Haemodialysis & $19(5.8)$ \\
\hline Constipation & $47(11.3)$ \\
\hline NSAIDs, LDA & $64(19.6)$ \\
\hline LDA, low-dose aspirin; NSAIDs, nonsteroidal anti-inflammatory & drugs; OGIB, obscure gastrointestinal \\
bleeding; SD, standard deviation & \\
\hline PatenCV evaluattiOn & \\
\hline
\end{tabular}

\section{Patency evaluation}

Figure 1 presents the flow diagram of the study. We found that $46.9 \%$ of the participants excreted a visually intact PC within $30 \mathrm{~h}$ and that $32.5 \%$ needed plain CT judgement when the PC was confirmed inside the body within 30-33 $\mathrm{h}$ after ingestion by X-ray (judgement time). The confirmed patency rate was $82.5 \%$. In 41 (12.6\%) patients, the PC could not be detected via X-ray during the judgement time, thereby judged as 'estimated patency'. The overall patency rate was $95.1 \%$, whereas the no-patency rate was $4.9 \%$ (Table 2 ). 
Table 2

Results of the patency capsule procedure

\begin{tabular}{|ll|}
\hline Overall patency, $\mathrm{n}(\%)$ & $\mathbf{3 1 0}(\mathbf{9 5 . 1})$ \\
\hline Confirmed patency, $\mathrm{n}(\%)$ & $269(82.5)$ \\
\hline Estimated patency, $\mathrm{n}(\%)$ & $41(12.6)$ \\
\hline CT judgement, $\mathrm{n}(\%)$ & $106(32.5)$ \\
\hline No patency, $\mathrm{n}(\%)$ & $16(4.9)$ \\
\hline Adverse events & $3(0.9)$ \\
Retention of the coating film & $1(0.3)$ \\
Abdominal pain & $1(0.3)$ \\
Nausea, vomiting & $1(0.3)$ \\
Intestinal obstruction & 0 \\
Perforation & 0 \\
Capsule aspiration & 0 \\
Allergic reaction & 0 \\
\hline CT, computed tomography & \\
\hline
\end{tabular}

\section{Factors associated with PC excretion within $30 \mathrm{~h}$}

Factors associated with PC excretion within $30 \mathrm{~h}$ are presented in Table 3. Univariate analysis showed that age, OGIB, inpatient, diabetes mellitus, haemodialysis and constipation significantly contributed to excretion inability within $30 \mathrm{~h}(P<0.05)$. In multivariate analysis, eight factors were analysed, and among them, age, female and inpatient were the independently influencing factors associated with $\mathrm{PC}$ excretion within $30 \mathrm{~h}(P<0.05)($ Table 3$)$. 
Table 3

Univariate and multivariate logistic regression analyses of factors associated with excretion within $30 \mathrm{~h}$ Univariate analysis

Multivariate analysis

\begin{tabular}{|c|c|c|c|c|c|c|}
\hline Factor & $\begin{array}{l}\text { Crude } \\
\text { OR }\end{array}$ & $95 \% \mathrm{Cl}$ & $\begin{array}{l}P \\
\text { value }\end{array}$ & $\begin{array}{l}\text { Adjusted } \\
\text { OR }\end{array}$ & $95 \% \mathrm{Cl}$ & $\begin{array}{l}P \\
\text { value }\end{array}$ \\
\hline Age & 0.978 & $\begin{array}{l}0.968- \\
0.989\end{array}$ & 0.0001 & 0.970 & $\begin{array}{l}0.970- \\
0.997\end{array}$ & 0.0139 \\
\hline Sex, F & 0.648 & $\begin{array}{l}0.412- \\
1.020\end{array}$ & 0.0596 & 0.541 & $\begin{array}{l}0.329- \\
0.891\end{array}$ & 0.0157 \\
\hline OGIB & 0.447 & $\begin{array}{l}0.281- \\
0.710\end{array}$ & 0.0006 & 0.680 & $\begin{array}{l}0.377- \\
1.230\end{array}$ & 0.2020 \\
\hline CD, established & 1.600 & $\begin{array}{l}0.930- \\
2.770\end{array}$ & 0.0893 & 0.626 & $\begin{array}{l}0.322- \\
1.220\end{array}$ & 0.1670 \\
\hline CD, suspected & 1.530 & $\begin{array}{l}0.518- \\
4.500\end{array}$ & 0.4430 & & & \\
\hline $\begin{array}{l}\text { Inflammatory } \\
\text { diseases }\end{array}$ & 1.570 & $\begin{array}{l}0.692- \\
3.570\end{array}$ & 0.2800 & & & \\
\hline Abdominal pain & 0.838 & $\begin{array}{l}0.379- \\
1.850\end{array}$ & 0.6620 & & & \\
\hline Small-bowel tumour & 1.630 & $\begin{array}{l}0.611- \\
4.370\end{array}$ & 0.3280 & & & \\
\hline Intestinal obstruction & 1.020 & $\begin{array}{l}0.168- \\
6.200\end{array}$ & 0.9820 & & & \\
\hline Inpatient & 0.424 & $\begin{array}{l}0.268- \\
0.670\end{array}$ & 0.0002 & 0.381 & $\begin{array}{l}0.226- \\
0.643\end{array}$ & 0.0003 \\
\hline History of surgery & 0.985 & $\begin{array}{l}0.616- \\
1.570\end{array}$ & 0.9480 & & & \\
\hline Diabetes mellitus & 0.339 & $\begin{array}{l}0.183- \\
0.630\end{array}$ & 0.0006 & 0.610 & $\begin{array}{l}0.298- \\
1.250\end{array}$ & 0.1760 \\
\hline Haemodialysis & 0.374 & $\begin{array}{l}0.143- \\
0.978\end{array}$ & 0.0448 & 1.000 & $\begin{array}{l}0.341- \\
2.940\end{array}$ & 0.9990 \\
\hline Constipation & 0.363 & $\begin{array}{l}0.192- \\
0.686\end{array}$ & 0.0018 & 0.544 & $\begin{array}{l}0.264- \\
1.120\end{array}$ & 0.0997 \\
\hline NSAIDs & 1.390 & $\begin{array}{l}0.578- \\
3.360\end{array}$ & 0.4600 & & & \\
\hline
\end{tabular}

$\mathrm{CD}$, Crohn's disease; $\mathrm{Cl}$, confidence interval; NSAID, nonsteroidal anti-inflammatory drug; OGIB, obscure gastrointestinal bleeding; OR, odds ratio. 
We found 16 patients whose PC did not confirm patency. Table 4 summarises the patient characteristics, and Supplementary Table S1 lists the details of individual clinical information. Eight patients had established CD. Univariate analysis showed that established CD was significantly associated with patency loss $(P<0.05)$. In multivariate analysis, six factors were analysed, and among them, established $\mathrm{CD}$ and inpatient were the independently influencing factors associated with patency loss $(P<0.05)$ (Table 5).

Table 4

Characteristics of the no patency

\begin{tabular}{|ll|}
\hline Numbers of patients & 16 \\
\hline Sex, male/female & $11 / 5$ \\
\hline Age, mean \pm SD (range), years & $51.4 \pm 19.4(21-81)$ \\
\hline Inpatient/outpatient & $8 / 8$ \\
\hline History of abdominal surgery, n (\%) & $8(50.0)$ \\
\hline Reason for examination, $n$ (\%) & $3(18.8)$ \\
\hline OGIB & $8(50.0)$ \\
\hline Crohn's disease, established & $0(0.0)$ \\
\hline Crohn's disease, suspected & $2(12.5)$ \\
\hline Other inflammatory diseases & $0(0.0)$ \\
Abdominal pain & $1(6.3)$ \\
Small-bowel tumour & $0(0.0)$ \\
\hline Intestinal obstruction & $2(12.5)$ \\
\hline Others & \\
\hline Diabetes mellitus & $2(12.5)$ \\
\hline Haemodialysis & $2(12.5)$ \\
\hline Constipation & $2(12.5)$ \\
\hline NSAIDs, LDA & $1(6.3)$ \\
\hline LDA, low-dose aspirin; NSAIDs, nonsteroidal anti-inflammatory & drugs; OGIB, obscure gastrointestinal \\
bleeding; SD, standard deviation & \\
\hline
\end{tabular}


Table 5

Univariate and multivariate logistic regression analyses of factors associated with intestinal patency univariate analysis multivariate analysis

\begin{tabular}{|c|c|c|c|c|c|c|}
\hline Factor & $\begin{array}{l}\text { Crude } \\
\text { OR }\end{array}$ & $95 \% \mathrm{Cl}$ & $\begin{array}{l}P \\
\text { value }\end{array}$ & $\begin{array}{l}\text { Adjusted } \\
\text { OR }\end{array}$ & $95 \% \mathrm{Cl}$ & $P$ value \\
\hline Age & 1.000 & $\begin{array}{l}0.980- \\
1.020\end{array}$ & 0.8730 & 0.982 & $\begin{array}{l}0.9520- \\
1.010\end{array}$ & 0.2300 \\
\hline Sex, F & 1.450 & $\begin{array}{l}0.491- \\
4.270\end{array}$ & 0.5030 & 1.180 & $\begin{array}{l}0.3800- \\
3.650\end{array}$ & 0.7760 \\
\hline OGIB & 2.520 & $\begin{array}{l}0.703- \\
9.030\end{array}$ & 0.1560 & 2.250 & $\begin{array}{l}0.4790- \\
10.60\end{array}$ & 0.3040 \\
\hline CD, established & 0.276 & $\begin{array}{l}0.010- \\
0.762\end{array}$ & 0.0013 & 0.215 & $\begin{array}{l}0.0552- \\
0.840\end{array}$ & 0.0270 \\
\hline Other IDs & 0.668 & $\begin{array}{l}0.144- \\
3.090\end{array}$ & 0.6060 & & & \\
\hline $\begin{array}{l}\text { Small-bowel } \\
\text { tumour }\end{array}$ & 0.979 & $\begin{array}{l}0.123- \\
7.810\end{array}$ & 0.9840 & & & \\
\hline Inpatient & 0.472 & $\begin{array}{l}0.171- \\
1.300\end{array}$ & 0.1460 & 0.298 & $0.096-0.919$ & 0.0035 \\
\hline History of surgery & 0.476 & $\begin{array}{l}0.174- \\
1.310\end{array}$ & 0.1490 & 0.868 & $0.277-2.730$ & 0.8090 \\
\hline Diabetes mellitus & 1.310 & $\begin{array}{l}0.290- \\
5.960\end{array}$ & 0.7230 & & & \\
\hline Haemodialysis & 0.406 & $\begin{array}{l}0.009- \\
1.930\end{array}$ & 0.2580 & & & \\
\hline Constipation & 1.190 & $\begin{array}{l}0.261- \\
5.410\end{array}$ & 0.8230 & & & \\
\hline
\end{tabular}

$\mathrm{CD}$, Crohn's disease; $\mathrm{Cl}$, confidence interval; IDs, inflammatory diseases; OGIB, obscure gastrointestinal bleeding; OR, odds ratio 
Table 6

Results of the SBCE procedure

\begin{tabular}{|ll|}
\hline SBCE examination, \% & $\mathbf{3 0 2}(\mathbf{9 2 . 6 )}$ \\
\hline Total small-bowel observation, \% & $281(93.1)$ \\
\hline Transit time, minutes & $51.7 \pm 71.1$ \\
Stomach & $257.9 \pm 150.2$ \\
Small bowel & \\
\hline Positive findings, \% & $223(73.8)$ \\
Ulceration, erosions & $140(46.4)$ \\
Vascular lesions & $51(16.9)$ \\
Neoplasms & $44(14.6)$ \\
Others & $13(4.3)$ \\
\hline Adverse events & $1(0.3)$ \\
Capsule retention & 0 \\
\hline Capsule aspiration & \\
\hline SBCE, small-bowel capsule endoscopy \\
\hline
\end{tabular}

\section{Adverse events}

One of the adverse events caused by PC was the presence of residual coating film associated with stenosis in patients with CD. It was removed by double-balloon enteroscopy and treated by endoscopic balloon dilation. The mild adverse events were abdominal pain and vomiting, which were found in two patients separately (Supplementary Table S1).

\section{SBCE results}

SBCE was performed in 302 patients (92.6\%) who showed confirmed patency by PC examination. The rate at which the entire small bowel could be observed was $93.1 \%$ (mean small-bowel transit time, $257 \pm$ $150 \mathrm{~min}$ ). Meanwhile, only one (0.3\%) patient experienced capsule retention caused by a false CT judgement.

\section{Discussion}

In this study, we examined the validity of our modification on the passage criteria suitable for daily clinical practice and evaluated the safety and usefulness of PC in our consecutive patients. Our main findings were as follows. The overall patency rate was 95.1\%, $41(12.6 \%)$ patients were judged as having estimated patency, and SBCE was performed safely. In addition, $32.5 \%$ of the participants needed CT judgement. According to our passage criteria, one (0.3\%) SBCE case resulted in capsule retention because 
of a false CT judgement. Multivariate analysis revealed that established CD and inpatient were the factors independently related to patency loss $(P<0.05)$. Therefore, our modification on the passage criteria tailored for daily clinical practice seemed to be reasonable, keeping in mind CT misjudgement.

One of the main purposes of this study was to determine whether 'estimated patency' without retesting is valid in identifying patency for SBCE. Premature dissolution of the Agile $\mathrm{T}^{\mathrm{TM}}$ patency device was reported to occur, with at least an incidence of $1.3 \%$ in Europe, possibly the cause of unexpected capsule retention [24]. This event was recognised by the detection of a persistent radiofrequency signal after radiological imaging had failed to identify the patency device. In Japan, patients who need to undergo a patencytesting procedure can avail insurance if an intact capsule or intact body with an eroded timer plug is directly detected or if PC entry into the colon is confirmed by X-ray or another imaging modality at 30-33 $\mathrm{h}$ after ingestion [17]. However, PC retesting is clinically difficult because it impairs the proper timing of the examination and patient acceptability. In this study, no case of SBCE retention in 'estimated patency' was found, suggesting the validity of our judgement method.

Another purpose of this study was to determine the validity of plain CT judgement after confirming the location of the PC inside the body. Candidates for the second imaging modality include plain or contrastenhanced CT [25], low-dose CT [18], X-ray tomography [19], abdominal ultrasonography [20], air enema and magnetic resonance imaging. Among them, plain CT is an objective method and is the easiest to use in Japan, although it exposes patients to radiation. In this study, capsule retention occurred in one $(0.3 \%)$ patient. This result seems to agree with the results of a recent large-scale multicentre study in Japan [21]. Our results suggested that the choice of plain $\mathrm{CT}$ as the second imaging modality is nearly valid. However, a misjudgement of CT was observed in one case. Other studies also revealed that CT misjudgement would be a non-negligible reason for SBCE retention after PC examination [21, 23]. Physicians performing PC examinations should be aware of this issue.

Moreover, multivariate analysis indicated that age, female and inpatient were the factors independently associated with PC excretion within $30 \mathrm{~h}$, and established $\mathrm{CD}$ and inpatient were the factors independently related to patency loss $(P<0.05)$. CD is a recognised factor related to patency loss, consistent with our results [26]. However, many reports indicated that inpatients are related to transit time but not to patency loss. Although the exact reason for this discrepancy remains unknown, our results showed that inpatients were more likely to have organic disorders, such as radiation enteritis and NSAIDinduced small-bowel mucosal injury. In addition, patients with impaired functional passage of the upper gastrointestinal tract might have been included. Physicians should also be aware that SBCE has a longer small-bowel transit time in the elderly and women, regardless of having patency loss.

Although the safety and usefulness of PC have been reported in larger-scale prospective studies in Japan [5], the methods may need to be modified in daily clinical practice. Watanabe et al. reported that extending the time to confirm functional patency to $72 \mathrm{~h}$ might be acceptable and increase the possibility to perform CE safely [23]. Meanwhile, Omori et al. reported that the 24-hour assessment method can be 
handled more easily and more useful clinically [22]. Our modification in this study also proposes a highly feasible use of PC in daily practice.

This study has several limitations. Firstly, it is a single-centre, single-arm, retrospective study, although the participants were consecutive patients in clinical practice. Secondly, the overall patency rate was high in this study because we included many patients with OGIB in addition to CD. Therefore, the number of cases might be statistically insufficient for the analysis of factors related to patency loss. Despite some limitations, our study certainly suggests that our modified criteria play a role in the real-world use of PCs in actual clinical practice. A prospective comparative study with a larger sample size and in multiple centres is required to verify these issues.

\section{Methods}

\section{Study design}

This single-centre, retrospective study conformed to the principles of the Declaration of Helsinki. In accordance with the Ethical Guidelines for Medical and Health Research Involving Human Subjects (Ministry of Education, Culture, Sports, Science and Technology and Ministry of Health, Labour and Welfare, Japan), informed consent was omitted, and study information, including the objectives, was disclosed on our hospital website with an opt-out approach. The Ethics Committee of Hamamatsu University School of Medicine in Japan reviewed and approved the study protocol (20-354).

We enrolled consecutive patients who underwent PC before SBCE between September 2012 and February 2020 in our hospital. All patients provided written informed consent for PC prior to SBCE. The inclusion criteria were patients with suspected small-bowel stenosis scheduled for PC-based evaluation before SBCE. Physicians reviewed the small-bowel stenosis according to the patients' medical records and interview. In particular, patients with stenotic symptoms but with unclear stenosis on imaging studies were enrolled. The exclusion criteria included patients with ongoing small-bowel obstruction, barium allergy and dysphagia.

\section{PC and SBCE procedures}

We used the tag-less PillCam ${ }^{\mathrm{TM}}$ PC (Covidien Japan, Medtronic, Japan), which has the same size and components as the conventional Agile ${ }^{T M} P C$ with a radiofrequency identification tag. After $12 \mathrm{~h}$ of fasting, patients swallowed the PC with water at 9 AM. After $2 \mathrm{~h}$, drinking water was allowed, and in the next $2 \mathrm{~h}$, a meal was provided. Excretion of the $\mathrm{PC}$ was confirmed visually using a $\mathrm{PC}$ recovery kit during bowel movement until their outpatient visit the following evening. Small-bowel patency was confirmed with a PC 30-33 h after its ingestion. 'Confirmed patency' was defined as the visual verification of an intact capsule (body and timer plugs are virtually intact) or intact body (body is intact and hard, but timer plugs have eroded) once excreted within $30 \mathrm{~h}$, or the entry of an intact capsule into the large bowel confirmed by plain X-ray examination and further examination by plain $\mathrm{CT}$, as necessary. Furthermore, 'estimated patency' was defined as the lack of PC evidence in the body via X-ray during the judgement 
time (30-33 $\mathrm{h}$ after ingestion). Within $7 \mathrm{~d}$, patients with confirmed and estimated patency underwent SBCE (PillCam ${ }^{T M}$ SB, Covidien Japan, Medtronic, Japan).

\section{Endpoints}

The primary endpoint was the 'confirmed patency' and 'estimated patency' rates evaluated by smallbowel examination with $\mathrm{PC}$, and then the SBCE retention rate. The secondary endpoints were the CT judgement rate, adverse events, factors associated with patency loss and factors associated with excretion within $30 \mathrm{~h}$.

\section{Statistical analysis}

All statistical data were analysed using SPSS for Windows, version 16.0 (SPSS Inc., Chicago, Illinois, USA) and EZR (Saitama Medical Centre, Jichi Medical University, Saitama, Japan). Categorical data were

evaluated using $\chi^{2}$-test and Fisher's exact test. Factors associated with the nonconfirmation of PillCam ${ }^{\mathrm{TM}}$ PC-based gastrointestinal patency were identified by univariate and multivariate logistic regression analyses, and the results are expressed as crude and adjusted odds ratios (ORs) with $95 \%$ confidence intervals (Cls). The relationship between the period of time from PC ingestion to patency confirmation and the total enteroscopy rate was analysed using the Mann-Whitney $U$ test. Differences were considered significant if their $P$ values were less than 0.05 . $P C$ is useful for examining gastrointestinal patency prior to SBCE in clinical practice. In the judgement of patency, if the PC cannot be detected in the body by X-ray, performing SBCE as 'estimated patency' seems appropriate. Although plain CT is commonly used after PC detection via X-ray, physicians should be aware that the PC is difficult to locate accurately.

\section{Declarations}

Funding: This research was supported by Grants-in-Aid for Scientific Research (C) 19K08466 from the Ministry of Education, Culture, Sports, Science and Technology, Japan.

\section{Competing interests:}

The authors declare no competing interests.

Author contributions: Takahiro Miyazu and Satoshi Osawa contributed to the study concept and design, analysis and interpretation of data and draughting of the manuscript. Natsuki Ishida, Tomoharu Matsuura, Shinya Tani, Satoshi Tamura and Yasushi Hamaya contributed to patient management, acquisition of data of patency capsule and SBCE. Mihoko Yamade and Moriya Iwaizumi contributed to analysis and interpretation of data. Takahisa Furuta was involved in study supervision. Ken Sugimoto and Satoshi Osawa critically revised the manuscript for important intellectual content. All authors approved the final manuscript version prior to submission.

\section{Abbreviations}


BAE

balloon-assisted enteroscopy

CD

Crohn's disease

CT

computed tomography

NSAID

nonsteroidal anti-inflammatory drug

OGIB

obscure gastrointestinal bleeding

PC

patency capsule

SBCE

small-bowel capsule endoscopy

\section{References}

1. Iddan, G., Meron, G., Glukhovsky, A. \& Swain, P. Wireless capsule endoscopy. Nature, 405 (6785), 417 (2000).

2. Enns, R. A. et al. Clinical Practice Guidelines for the Use of Video Capsule Endoscopy., 152 (3), 497514 (2017).

3. Hosoe, N., Takabayashi, K., Ogata, H. \& Kanai, T. Capsule endoscopy for small-intestinal disorders: Current status. Dig Endosc, 31 (5), 498-507 (2019).

4. Esaki, M. et al. Capsule endoscopy findings for the diagnosis of Crohn's disease: a nationwide casecontrol study. J Gastroenterol, 54 (3), 249-260 (2019).

5. Rondonotti, E. et al. Small-bowel capsule endoscopy and device-assisted enteroscopy for diagnosis and treatment of small-bowel disorders: European Society of Gastrointestinal Endoscopy (ESGE) Technical Review. Endoscopy, 50 (4), 423-446 (2018).

6. Gerson, L. B., Fidler, J. L., Cave, D. R. \& Leighton, J. A. ACG Clinical Guideline: Diagnosis and Management of Small Bowel Bleeding. Am J Gastroenterol, 110 (9), 1265-1287 quiz 1288. (2015).

7. Wang, Y. C. et al. Adverse events of video capsule endoscopy over the past two decades: a systematic review and proportion meta-analysis. BMC Gastroentero/ 2020, 20(1):364.

8. Rezapour, M., Amadi, C. \& Gerson, L. B. Retention associated with video capsule endoscopy: systematic review and meta-analysis. Gastrointest Endosc, 85 (6), 1157-11681152 (2017).

9. Esaki, M. et al. Use of capsule endoscopy in patients with Crohn's disease in Japan: a multicenter survey. J Gastroenterol Hepatol, 29 (1), 96-101 (2014).

10. Rondonotti, E. Capsule retention: prevention, diagnosis and management. Ann Trans/ Med, 5 (9), 198 (2017). 
11. Makipour, K. et al. Double balloon enteroscopy: effective and minimally invasive method for removal of retained video capsules. Dig Endosc, 26 (5), 646-649 (2014).

12. Spada, C. et al. A novel diagnostic tool for detecting functional patency of the small bowel: the Given patency capsule. Endoscopy, 37 (9), 793-800 (2005).

13. Herrerias, J. M. et al. Agile patency system eliminates risk of capsule retention in patients with known intestinal strictures who undergo capsule endoscopy. Gastrointest Endosc, 67 (6), 902-909 (2008).

14. Silva, M., Cardoso, H. \& Macedo, G. Patency Capsule Safety in Crohn's Disease. J Crohns Colitis, 11 (10), 1288 (2017).

15. Nakamura, M. et al. Clinical usefulness of novel tag-less Agile patency capsule prior to capsule endoscopy for patients with suspected small bowel stenosis. Dig Endosc, 27 (1), 61-66 (2015).

16. Nakamura, M., Kawashima, H., Ishigami, M. \& Fujishiro, M. Indications and Limitations Associated with the Patency Capsule Prior to Capsule Endoscopy. Intern Med2021.

17. Yamamoto, H. et al. Clinical Practice Guideline for Enteroscopy. Dig Endosc, 29 (5), 519-546 (2017).

18. Shirasawa, T. et al. Effectiveness of using low-dose computed tomography to assess patency in gastrointestinal tracts with a patency capsule. Hepatogastroenterology, 62 (137), 240-244 (2015).

19. Omori, T., Nakamura, S. \& Shiratori, K. Localization of the Patency Capsule by Abdominal Tomosynthesis. Digestion, 91 (4), 318-325 (2015).

20. Shiotani, A. et al. Clinical relevance of patency capsule combined with abdominal ultrasonography to detect small bowel strictures. Eur J Gastroenterol Hepatol, 26 (12), 1434-1438 (2014).

21. Nakamura, M. et al. Tag-less patency capsule for suspected small bowel stenosis: Nationwide multicenter prospective study in Japan.Dig Endosc2020.

22. Omori, T. et al. Evaluation of Intestinal Patency with the Patency Capsule: The Twenty-Four Hour Assessment Method. Digestion, 100 (3), 176-185 (2019).

23. Watanabe, K., Ohmiya, N., Nakamura, M. \& Fujiwara, Y. A Prospective Study Evaluating the Clinical Utility of the Tag-Less Patency Capsule with Extended Time for Confirming Functional Patency.Digestion2019:1-8.

24. Wray, N. et al. Premature dissolution of the Agile patency device: implications for capsule endoscopy. Frontline Gastroenterol, 10 (3), 217-221 (2019).

25. Mitselos, I. V., Katsanos, K., Tsianos, E. V., Eliakim, R. \& Christodoulou, D. Clinical Use of Patency Capsule: A Comprehensive Review of the Literature. Inflamm Bowel Dis, 24 (11), 2339-2347 (2018).

26. Pasha, S. F. et al. Capsule Retention in Crohn's Disease: A Meta-analysis. Inflamm Bowel Dis 2020, 26(1):33-42.

\section{Figures}


Figure 1

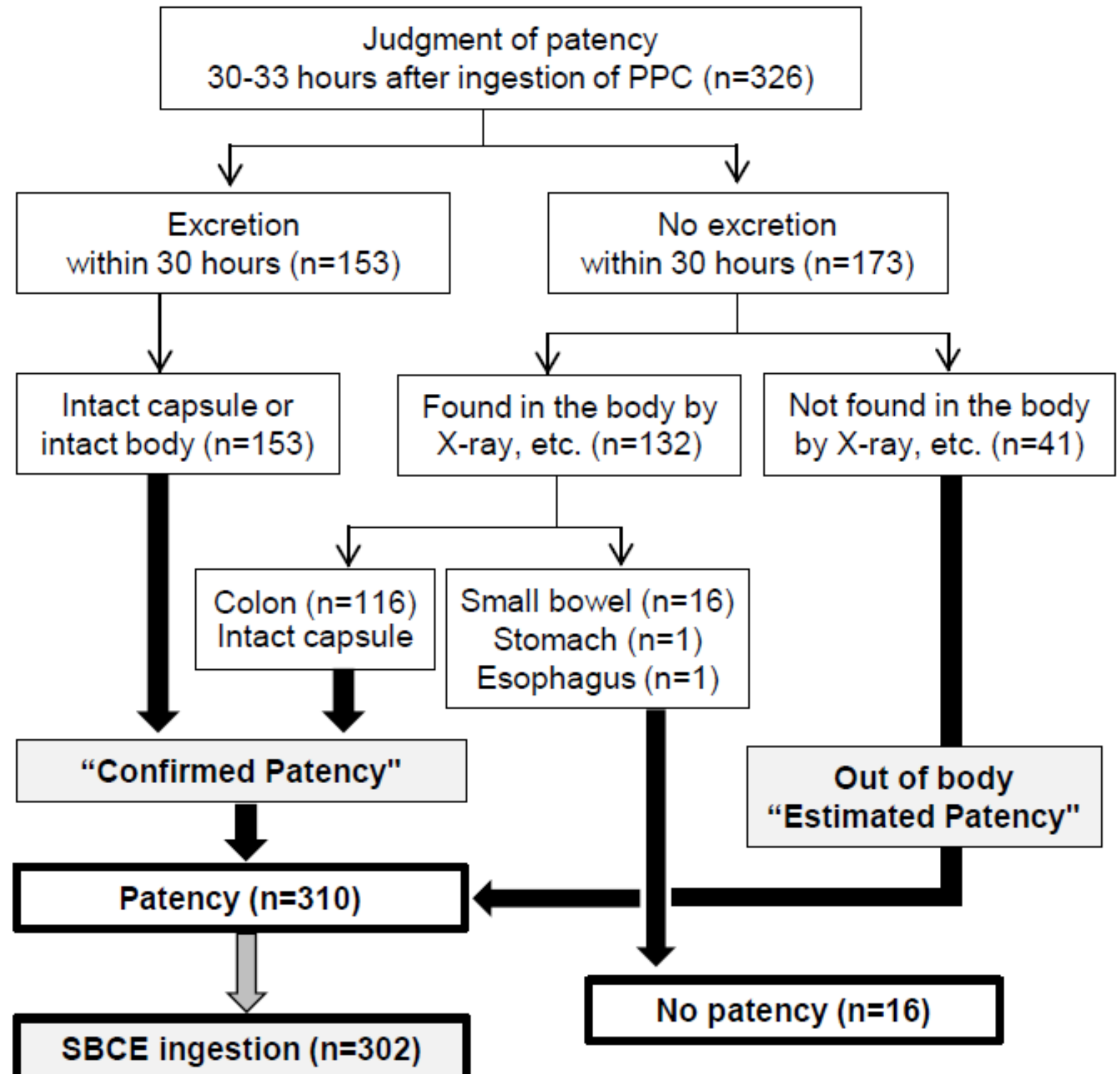

Figure 1

Study flow diagram 
Figure 2

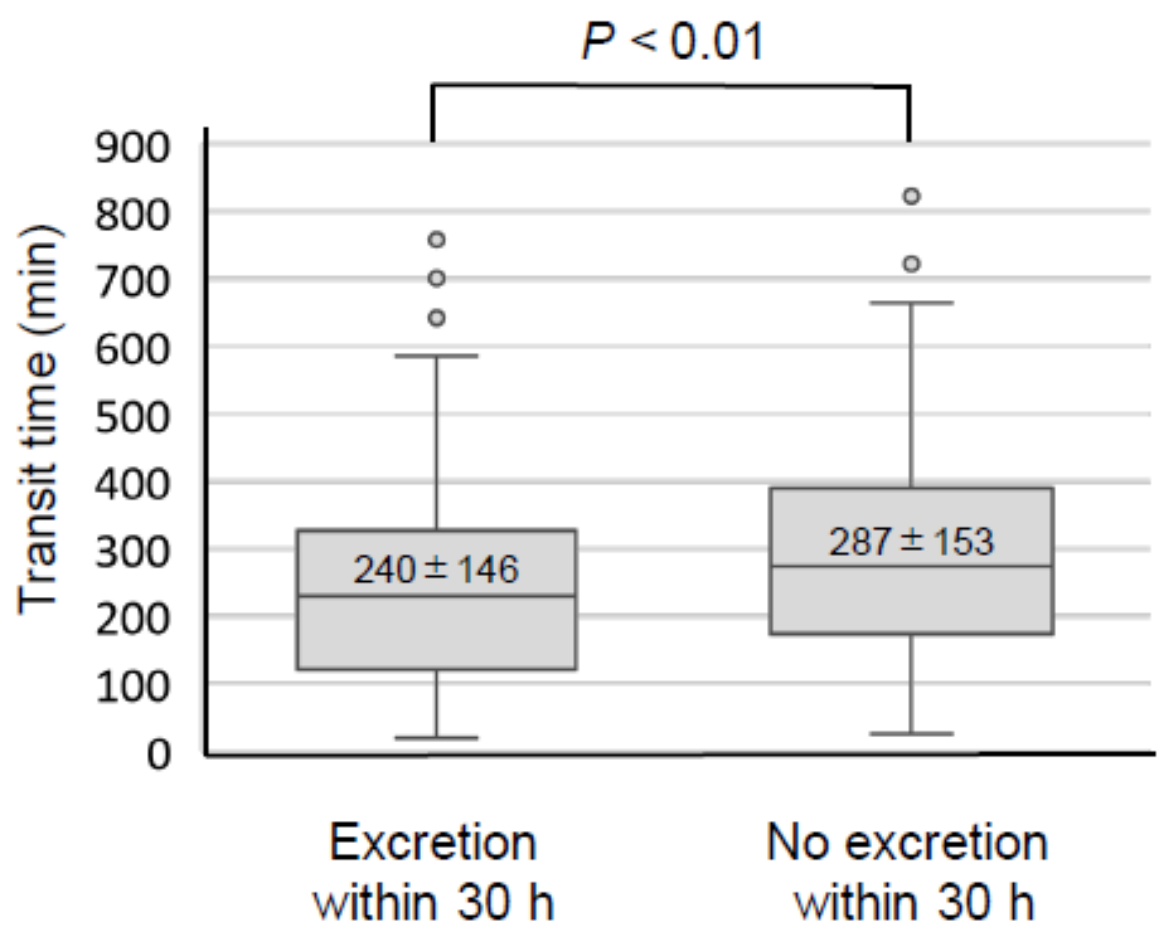

Figure 2

PC excretion within $30 \mathrm{~h}$ was associated with SBCE transit time The transit time of the small-bowel capsule endoscopy (SBCE) was compared between the excretion and nonexcretion groups within $30 \mathrm{~h}$. 


\section{Figure 3}
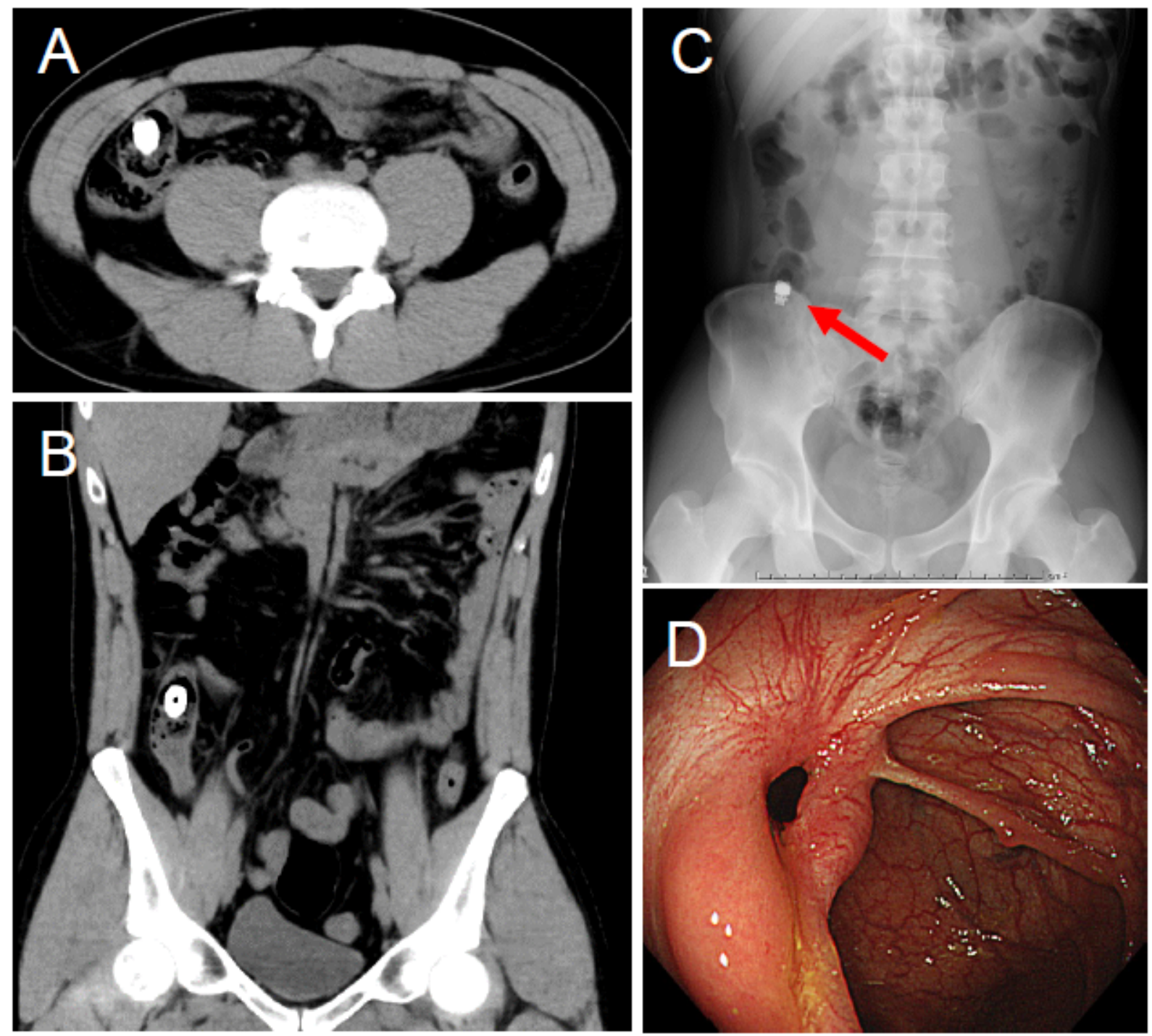

\section{Figure 3}

SBCE retention case caused by CT misjudgement of PC in a patient with Crohn's disease Plain computed tomography (CT) images show that the PC seemed to be in the ascending colon; axial CT image (A), coronal CT image (B). X-ray scan confirms SBCE retention (arrow) in the terminal ileum after 2 weeks (C). Colonoscopic image confirms ileocecal valve stenosis, which was treated with balloon dilatation (D).

\section{Supplementary Files}


This is a list of supplementary files associated with this preprint. Click to download.

- MiyazuTetal.SupplementaryTableS1.docx 